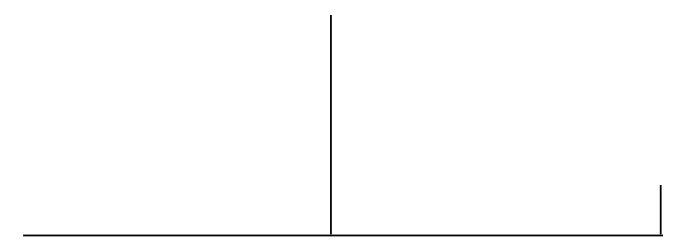

Rev. Latinoam. Psicopat. Fund., São Paulo, v. 15, n. 2, p. 323-349, junho 2012

\title{
Sífilis por "exposição normal" e inoculação: um médico da equipe do estudo Tuskegee na Guatemala, 1946-1948*
}

Susan M. Reverby

Entre 1946 e 1948, o Serviço de Saúde Pública dos Estados Unidos (PHS) e a Oficina Sanitária Panamericana, com a colaboração de funcionários de saúde pública do governo da Guatemala, realizaram um estudo sobre o uso da penicilina como possível profilaxia para a sífilis, gonorreia e cancro. Os "sujeitos" do estudo - prisioneiros, doentes mentais e soldados gualtematecos foram inoculados com essas doenças e também pelo contato com prostitutas infectadas. A fraude foi parte do estudo e os abusos éticos foram discutidos no PHS. Os resultados do estudo não foram publicados.

Palavras-chave: Sífilis, Guatemala, saúde pública, penicilina

* Publicado originalmente em The Journal of Policy History, v. 23, n. 1, 2001.

Tradução de Mônica Teixeira. 
Quero agradecer a Marianne Kasica, dos arquivos da Universidade de Pittsburgh, por me ajudar fazendo aquilo que todos os arquivistas deveriam fazer: tornar as informações de seus arquivos acessíveis a pesquisadores legítimos. Obrigada a Zachary Schrag pela edição, pelo incentivo e por suas perguntas e aos colegas presentes na primeira vez que apresentei este artigo, no encontro anual da American Association for the History of Medicine, em maio de 2010. Agradeço também os comentários do exdiretor do CDC, dr. David Sencer, que desconhecia os detalhes do estudo na Guatemala, que não ocorreu sob sua direção. Sem sua preocupação, conexões e respeito pela importância da história, a divulgação do estudo poderia nunca ter obtido resposta tão extraordinária. O dr. John Douglas, do CDC, fez um relatório incrível em curto prazo que confirmou meu trabalho e forneceu estatísticas claras sobre os sujeitos da pesquisa. Sou grata aos funcionários do governo dos Estados Unidos, que se prontificaram a reconhecer os erros cometidos, bem como àqueles que dedicaram tempo para refletir sobre o assunto, comunicar sua preocupação pública e privadamente e fazer parte da contínua luta pelo equilíbrio entre os direitos humanos e o progresso na medicina.

Com frequência, a adoção de políticas se baseia em interpretações históricas de eventos particulares, e o caso Tuskegee pode ter influenciado mais que qualquer outro experimento médico as políticas referentes ao uso de sujeitos humanos em pesquisas. ${ }^{1}$ Com duração de quarenta anos, o estudo "Sífilis não tratada em homens negros" provocou indignação em 1972 ao tornar-se público, e inspirou o estabelecimento de normas como

1. Tem sido debatido, especialmente na Universidade Tuskegee, se o estudo deveria ser chamado de Estudo Tuskegee ou de Estudo do Serviço de Saúde Pública Norte-americano sobre Sífilis não tratada em homens negros em Tuskegee para englobar os pesquisadores que conduziram o estudo com seu título mais formal. Como a pesquisa é principalmente conhecida por Estudo Tuskegee, eu uso o termo "Tuskegee" entre aspas ou me refiro a ele como "o estudo".

Rev. Latinoam. Psicopat. Fund., São Paulo, v. 15, n. 2, p. 323-349, junho 2012 
o consentimento informado, a proteção de sujeitos vulneráveis e a supervisão por parte dos conselhos de ética institucionais. ${ }^{2}$

Entretanto, histórias referentes ao estudo muitas vezes tornam-se míticas quando contadas. Os fatos comprovam que os médicos do Serviço de Saúde Pública Norte-americano (PHS, na sigla em inglês) que conduziram a pesquisa observaram a evolução da sífilis tardia latente não tratada em centenas de homens negros do condado de Macon, no Alabama. Nos primeiros meses de 1932, eles forneceram pequenas doses de tratamento, mas, a partir daí, não administraram nenhum tratamento extensivo com penicilina ou metais pesados, embora estes já tivessem sua eficácia comprovada na cura de muitos casos da doença em estágio tardio. ${ }^{3}$ De acordo com os rumores acerca do estudo, porém, a negligência não se limitou à omissão do tratamento - os médicos teriam secretamente infectado os sujeitos injetando-os com a bactéria que provoca a sífilis. $\mathrm{O}$ boato sobre a infecção intencional do PHS se alastrou como pólvora e aparece quase diariamente em livros, artigos, palestras, cartas, web sites, tweets, notícias, retórica política e, sobretudo, em sussurros e conversas. A crença é reforçada quando circulam fotografias de exames de sangue, em especial aquelas recortadas de modo a mostrar em primeiro plano um braço negro e uma mão branca segurando uma seringa que, para olhos leigos, poderia ser tomada por uma injeção.

Há décadas historiadores do caso estão tentando corrigir as falsas interpretações do público e do meio acadêmico e trazer os fatos à tona, na medida do possível. ${ }^{4}$ A história é terrível o suficiente, argumentam, sem que haja

2. Susan M. Reverby. Examining Tuskegee: The Infamous Syphilis Study and Its Legacy Chapel. Hill, NC: University of North Carolina Press, 2009. p. 187-203.

3. Havia também um debate durante a década de 1950 sobre se a penicilina deveria ser administrada aos pacientes no estágio latente tardio da doença. A norma entre os médicos era tomar a decisão caso a caso. Isso não foi feito no estudo. Ainda é controverso se as esposas/parceiras sexuais dos homens foram tratadas. Nos registros médicos atualmente disponíveis (nos Arquivos Nacionais da Southeast Regional em Morrow, Georgia), a informação sobre o tratamento das esposas está riscada para proteger sua identidade, o que torna impossível avaliar as alegações de que as esposas, em fase contagiosa, receberam tratamento. Quando o estudo foi finalizado, o PHS concordou em tratar vinte e duas esposas, dezessete filhos e dois netos que obtiveram resultado positivo para sífilis. Para saber mais sobre como isso foi determinado, ver Susan M. Reverby, "The 'Tuskegee' Syphilis Study as a 'Site of Memory"'. In: The Search for the "Legacy" of the U.S. Public Health Syphilis Study at Tuskegee, ed. Ralph Katz and Rueben Warren (Lanham, Md.).

4. James H. Jones. Bad Blood. Rev. ed. (New York, 1993); Susan M. Reverby (ed.). Tuskegee's Truths: Rethinking the Tuskegee Syphilis Study (Chapel Hill, 2000); Reverby, Examining Tuskegee. 
necessidade de perpetuar os mal-entendidos sobre o que aconteceu e sobre quantos sabiam do ocorrido. ${ }^{5}$ Mas e se realmente o PHS tenha conduzido uma pesquisa um tanto quanto secreta cujos sujeitos foram infectados com sífilis por um dos médicos do centro que também trabalhou em Tuskegee? De que maneira isso deve ser reconhecido e como deve influenciar a abordagem de interpretações históricas que motivam a necessidade de proteção de sujeitos humanos?

\section{Boatos e realidades}

Pesquisadores que desejam derrubar o mito da infecção deliberada no estudo Tuskegee podem reconhecer que os mitos às vezes expressam certas realidades básicas. Como argumenta o especialista em história oral Alessandro Portelli, "relatos equivocados permitem-nos reconhecer os interesses de quem conta a história, bem como os sonhos e desejos subjacentes a ela". 6 "Um rumor, sugere outro folclorista, é uma forma de comunicação através da qual homens e mulheres presos a uma situação ambígua procuram interpretá-la de maneira coerente, unindo seus recursos intelectuais." ${ }^{\prime 7} \mathrm{Em}$ um país fortemente racista e racialmente dividido, a ideia de que cientistas do governo - embriagados com o poder que detinham sobre um grupo de crédulos pequenos agricultores necessitados de cuidados médicos - teriam deliberada e secretamente infectado homens negros com uma doença debilitante, e em certos casos mortal, parece plausível.

Não obstante, os pesquisadores podem também argumentar que as pessoas que acreditam na infecção deliberada estão confundindo este estudo com outras histórias de horror ocorridas nos Estados Unidos nas décadas de 1960 e 1970, quando médicos pesquisadores excessivamente entusiasmados injetaram células cancerosas em pacientes judeus idosos e administraram células vivas de hepatite por via oral ou intravenosa em crianças pequenas com retardo mental. A confusão se agrava quando se faz referência ao estudo como o "Nuremberg Norte-americano" (equiparando seus efeitos na ética), vinculando-o aos horrores dos monstruosos experimentos médicos nazistas. Além disso, a ideia de que homens tenham sido infectados penetra profundamente no medo da experimen-

5. Para maiores detalhes e cronologia do estudo, ver http://www.examiningtuskegee.com. O estudo não era um segredo. Mais de dez artigos foram publicados sobre ele em revistas médicas diversas.

6. Alessandro Portelli. The Death of Luigi Trastulli and Other Stories (Albany, N.Y.,1990), 2.

7. Sociólogo Tamotsu Shibutani, citado em Whispers on the Color Line: Rumor and Race in America, ed. Patricia Turner and Gary Alan Fine (Berkeley and Los Angeles, 2004), 58-59. 
tação de nossa consciência cultural coletiva. Ela evita ainda que tenhamos de considerar as atividades sexuais dos participantes involuntários do estudo, bem como a de seus pais, uma vez que a sífilis é, primariamente, uma doença sexualmente transmissível. ${ }^{8}$ Supor que os sujeitos da pesquisa tenham sido infectados em vez de observados por décadas parece reforçar ainda mais o racismo, embora a naturalidade com que o tratamento foi negado seja aquilo que deveria nos assustar mais do que tudo. ${ }^{9}$

Historiadores e outros estudiosos argumentam também que a pertinência do tratamento com metais pesados para os portadores da doença em estágio latente tardio foi debatida e que a missão dos órgãos de saúde pública era eliminar o contágio, e não enfocar a doença crônica. Outros defendem que a preocupação quanto aos perigos da penicilina limitou seu uso, sobretudo em pacientes que haviam contraído a infecção sifilítica há pelo menos duas décadas. ${ }^{10}$

Os historiadores podem ainda enfatizar as interpretações médicas dos estágios da sífilis e de sua transmissão. Essa explicação requer uma discussão sobre as múltiplas fases da doença, e sobre quando e como as decisões sobre o tratamento dos portadores da sífilis em estágio latente foram tomadas. Mais importante: mesmo que os médicos do governo quisessem contagiar os sujeitos, é muito difícil transmitir a doença sem que haja contato sexual, amamentação ou de forma congênita, de uma mãe infectada para o feto. Esclarecer essa questão pressupõe também confrontar as crenças, anteriores ao século XX, de que a sífilis seria hereditária, não apenas congênita, já que ela não pode ser transmitida pelos genes nem por linhagem sanguínea. Pressupõe ainda esclarecer que os médicos não conseguiriam passar sem dificuldades a bactéria espiroqueta, que causa a sífilis do sangue, de uma pessoa para a outra, e que séculos de pesquisas demonstraram as dificuldades de recriar em laboratório a enfermidade em pessoas saudáveis. ${ }^{11}$ A bactéria espiralada da sífilis não é cultivável in vitro (ao contrário da N.gonorrhoea, que pode ser cultivada em laboratório).

8. O estereótipo sobre os homens negros serem altamente sexualizados também precisa ser confrontado.

9. Susan M. Reverby. "More than Fact and Fiction: Cultural Memory and the Tuskegee Syphilis Study". Hastings Center Report 31 (September-October 2001), p. 22-28.

10. Para várias versões dessa discussão, ver Thomas G. Benedek and Jonathan Erlen, "The Scientific Environment of the Tuskegee Study of Syphilis, 1920-1960". Perspectives in Biology and Medicine 45 (Autumn 1999 ), p. 1-30; Richard Shweder, "Tuskegee Re-Examined", Spiked online, www.spiked-online.com, 8 January 2004; Robert W. White, "Unraveling the Tuskegee Study of Untreated Syphilis", Archives of Internal Medicine 160 (13 March 2000), p. 585-98.

11. Joan Sherwood. "Syphilization: Human Experimentation in the Search for a Syphilis Vaccine in the Nineteenth Century", Journal of the History of Medicine 54 (July 1999), p. 364-86; and 
Em síntese, é preciso tempo e comprometimento para apreender a ciência médica, entender as práticas padronizadas do sistema de saúde pública e considerar as crenças culturais do público leigo e da área de saúde para explicar por que os homens do Alabama não foram, e não poderiam ter sido facilmente infectados pelo PHS e por que, apesar disso, essa crença persiste. Contar uma história simplista, que soe bem, é um recurso melhor empregado na retórica midiática ou política, ou em uma breve introdução histórica de uma lição superficial de bioética.

Ironicamente, porém, a versão mítica do estudo Tuskegee pode oferecer uma imagem mais correta da ética do PHS em meados da década de 1950 do que os relatos aparentemente melhor informados: com efeito, pesquisadores do órgão infectaram deliberadamente homens $e$ mulheres com sífilis com o objetivo de estudar a doença. O equívoco é situar a história no Alabama, quando na realidade ela se passou mais ao sul, mais precisamente, na Guatemala.

O caso da Guatemala emerge dos registros do trabalho realizado pelo dr. John C. Cutler, médico do PHS, entre 1946 e 1948, atualmente arquivados na Universidade de Pittsburgh. ${ }^{12}$ Administrador e pesquisador em saúde pública de renome internacional e especialista em doenças sexualmente transmissíveis e saúde reprodutiva, Cutler foi subdiretor geral de saúde pública no PHS e subdiretor do Pan American Sanitary Bureau (precursor da Pan American Health Organization). ${ }^{13}$ Tendo trabalhado na Guatemala, Índia e Haiti, ele encerrou sua carreira, conforme consta em seu obituário, como "professor muito querido da Graduate School of Public Health e da Graduate School of Public and International Affairs", ambas na Universidade de Pittsburgh. ${ }^{14}$

Susan E. Lederer, Subjected to Science: Human Experimentation in America Before the Second World War ( Baltimore, 1995).

12. Os registros foram doados ao Archives Service Center, da Universidade de Pittsburgh, em 1990, três anos antes de Cutler aparecer no vídeo "Deadly Deception". Atualmente os registros estão sendo avaliados para que se determine se devem tornar-se propriedade federal. Em caso positivo, serão transferidos para os Arquivos Nacionais.

13. Marcos Cueto. The Value of Health: A History of the Pan American Health Organization (Washington, D.C., 2007) argumenta que o período imediatamente posterior à guerra marcou um momento importante nas trocas "interamericanas" em saúde pública; ver também Pan American Sanitary Bureau, The Pan American Sanitary Bureau: A History of Its Organization, Function, and Activities (Mexico City, 1946). Sobre a expansão do bem-estar social durante a liberalização das políticas na Guatemala entre a Segunda Guerra e o golpe de estado apoiado pela CIA em 1954, ver Susanne Jonas, The Battle for Guatemala: Rebels, Death Squads, and U.S. Power (Boulder, 1991), p. 21-40.

14. Jan Ackerman, "Obituary: John Charles Cutler/Pioneer in Preventing Sexual Diseases", Pittsburgh Post-Gazette, 12 February 2003, www.post-gazette.com. Para mais sobre a carreira de Cutler, ver Reverby, Examining Tuskegee, 144-51. 
Cutler dedicava-se a pesquisar e a combater as DSTs (então conhecidas como doenças venéreas) e a oferecer métodos de contracepção utilizáveis e eficazes para mulheres. Ele publicou mais de cinquenta artigos sobre diversas doenças venéreas, sobre profilaxia com anticonceptivos químicos e sobre formas de acabar com a epidemia da AIDS. ${ }^{15}$ As pessoas familiarizadas com o estudo Tuskegee reconhecerão seu nome como o do ferrenho defensor do experimento nos anos 1960 que apareceu no documentário "The Deadly Deception", da série Nova do canal público norte-americano PBS, produzido em 1993, mais de vinte anos após o encerramento do estudo. ${ }^{16}$

Quase vinte anos antes de seu envolvimento com o estudo no Alabama, Cutler foi encarregado pelo PHS da direção de um projeto de pesquisa com duração de dois anos na Guatemala. Esse experimento realizado no hemisfério sul, e não no sul dos Estados Unidos, diferiu do estudo do Alabama, sobretudo por dois fatores: na Guatemala, os médicos do governo realmente infectaram pessoas com sífilis (além de gonorreia e cancroide) e então as trataram com penicilina. Neste programa de pesquisas cuidadosamente arquitetado, médicos do PHS expuseram seus sujeitos à sífilis através do contato com prostitutas infectadas ou diretamente por meio de inoculações feitas com gomas e cancros sifilíticos de tecido humano e animal, ou com pus de gonorreia e úlceras de cancroide. Depois de aprender o que podiam com cada exposição que se mostrou capaz de provocar uma infecção (nem todas o fizeram), eles fizeram uso da penicilina, supostamente para curá-la. ${ }^{17}$

15. A Pubmed - base de dados bibliográficos para pesquisas em medicina e biologia - lista seu nome em 58 artigos entre 1946 e 1995.

16. “The Deadly Deception”, NOVA. Videotape, PBS. Direção de Denise Dilanni. Boston: WGBH Educational Foundation Films for the Humanities and Sciences, 1993.

17. Depois de eu ter fornecido uma cópia deste artigo, previamente à sua publicação, aos funcionários do Centers for Disease Control and Prevention (ver adendo), o dr. John Douglas fez uma análise dos arquivos em Pittsburgh. Seu relatório "Findings from a CDC Report on the 1946-1948 U.S. Public Health Service Sexually Transmitted Disease (STD) Inoculation Study," (http://www.hhs.gov/1946inoculationstudy/findings/html (último acesso em 11 de outubro de 2010) analisou os registros médicos mais detalhadamente. De acordo com o dr. Douglas:

1. "Na série de estudos sobre a sífilis, um total de 696 sujeitos ou experimentos individuais foram expostos à infecção (por contato sexual ou inoculação). Destes, $427(61 \%)$ foram considerados infectados e entre eles 369 (86\%) receberam o que foi considerado 'tratamento adequado' com injeções de penicilina (definido pelos pesquisadores como $\geq 3.4$ milhões de unidades."

2. "Na série de estudos sobre gonorreia, um total de 772 sujeitos ou experimentos individuais foram expostos à infecção (por contato sexual ou inoculação). Destes, o relatório do experimento indica que 234 (30\%) foram infectados e entre eles $233(99,5 \%)$ teriam recebido 
Explorar o porquê de os experimentos na Guatemala terem sido tão diferentes daqueles realizados no Alabama contribui para compreendermos as inquietações éticas dos pesquisadores do PHS, a imperiosa atração da busca pelo conhecimento científico e a dificuldade de analisar a dinâmica e a inter-relação das pesquisas entre o que já se chamou de "periferia imperial" e as "transformações da metrópole". ${ }^{18}$

\section{Cura com penicilina ou profilaxia química?}

Ao final da Segunda Guerra, o uso da penicilina tornou-se mais generalizado e o medicamento começou a demonstrar sua eficácia na cura da sífilis primária e secundária, além de diversas outras doenças. ${ }^{19}$ No entanto, muitas questões quanto às doses e limitações da droga estavam por serem descobertas. Olhando para o futuro, pesquisadores da doença dos anos 1940 começaram a se dar conta, como lamentaria Joseph Aarle Moore, da Universidade de Johns Hopkins, dez anos mais tarde, "do pesar dos médicos clínicos atraídos pela biologia, já que a sífilis parecia estar desaparecendo deixando seus enigmas mais fascinantes e fundamentais sem solução". ${ }^{20}$

Uma dessas questões remanescentes consistia em investigar se havia necessidade de melhor profilaxia química, além do uso de preservativos, a ser aplicada diretamente no pênis depois de possível exposição à doença, ou se apenas a administração da penicilina por um profissional de saúde após diagnóstico positivo seria suficiente. ${ }^{21}$ Os pesquisadores da doença estavam conscientes dos

tratamento com injeções de penicilina (300.000 unidades).

3. "Nos estudos sobre cancroide ... um total de 152 sujeitos foram expostos à infecção por inoculação. Destes, o relatório do experimento indica que 128 (97\%) foram infectados, dos quais $129(93 \%)$ teriam recebido tratamento com sulfatiazol (1 grama PO por dia por 5 dias)."

18. Nancy Tomes , "Introduction: Imperial Medicine and Public Health", in Colonial Crucible: Empire in the Making of the Modern American State, ed. Alfred W. McCoy and Francisco A. Scarano (Madison, 2009), 273-76.

19. Harry F. Dowling. Fighting Infection: Conquests of the Twentieth Century (Cambridge, Mass., 1977), p. 125-57; John Parascandola, Sex, Sin, and Science (New York, 2008).

20. Citado em Reverby, Examining Tuskegee, 139. As questões pendentes quanto à biologia da sífilis voltaram à tona com aqueles que defendem que existe uma conexão entre a sífilis nãotratada e o vírus da AIDS. Ver Harris L. Coulter, AIDS and Syphilis - The Hidden Link (Berkeley and Los Angeles, 1993); and Coleman Jones, "Challenging Dissident Dogma: The Role of Infectious Co-Factors in AIDS", http://breakfornews.com/aidsmyth./news/ 000529syphilisdebate.htm (último acesso em 19 de março de 2010).

21. John C. Cutler. "Current Concepts of Prophylaxis", Bulletin of the New York Academy of Medicine 52 (October 1976 ), p. 866-96. Para um ponto de vista oposto ao adotado por Cutler 
problemas com muitas sorologias (exames de sangue) para determinar a sífilis, da dificuldade de traduzir testes realizados em animais (primariamente feitos em coelhos e amiúde em chimpanzés) para o organismo humano, da complicada cronicidade da doença e da astúcia da espiroqueta sifilítica que vinha fascinandoos há décadas.

Em 1944, o PHS realizara experimentos sobre profilaxia da gonorreia na Penitenciária Federal Terre Haute, nos Estados Unidos. Nesta prisão, os "voluntários" haviam sido deliberadamente injetados com gonorreia, mas o PHS encontrou dificuldades em fazer com que os sintomas da infecção aparecessem e o estudo foi abandonado. ${ }^{22}$ Para dar prosseguimento a esse trabalho, e estendê-lo à sífilis, o PHS olhou mais ao sul, para além das fronteiras norte-americanas.

O PHS tinha uma longa história de trabalho internacional que remontava ao século XIX, quando realizara quarentenas e conferências sanitárias sobre doenças infecciosas no exterior. Em 1945, um escritório de relações internacionais foi criado para formalizar esses esforços. ${ }^{23}$ Para coordenar o controle de enfermidades nas Américas, o órgão liderou a criação, em 1901, do Pan American Sanitary Bureau, e o diretor do PHS esteve à frente do órgão de 1902 a $1936 .{ }^{24}$ Nas palavras de um historiador, o Pan American Sanitary Bureau "funcionou até o final dos anos trinta praticamente como uma sucursal do PHS". ${ }^{25}$ A seu turno, muitos

pelo PHS sobre profilaxia, ver Joseph Earle Moore, The Modern Treatment of Syphilis, 2nd ed. (Springfield, Ill., 1943 ), p. 564-67. Sobre as tensões entre os médicos do PHS e Moore, ver John F. Mahoney to John C. Cutler, 19 April 1948, Box 1, Folder 13, John C. Cutler Papers, University Archives, University of Pittsburgh, Pittsburgh, Pa. (de agora em diante, Cutler Papers).

22. Os inóculos foram tanto cultivados quanto retirados do pênis de homens infectados e inseridos no pênis de outros. Ver John F. Mahoney et al., "Experimental Gonococcic Urethritis in Human Volunteers," American Journal of Syphilis, Gonorrhea, and Venereal Diseases 30 (January 1946): 1-39. Para mais sobre o debate sobre as políticas adotadas na pesquisa de Terre Haute, ver Harry M. Marks, The Progress of Experiment (New York, 1997), 100-105. Sobre o interesse reavivado em pesquisas em prisões, ver Institute of Medicine, Ethical Considerations for Research Involving Prisoners (Washington, D.C., 2006); Barron H. Lerner, "Subjects or Objects? Prisoners and Human Experimentation", New England Journal of Medicine 356 (3 May 2007), p. 1806-7.

23. Jeanne L. Brand. "The U.S. Public Health Service and International Health", Bulletin of the History of Medicine 63 (Winter 1989), p. 582-83.

24. Hugh S. Cumming, que ocupava o cargo de diretor geral no início do estudo "Tuskegee", foi diretor do Pan American Sanitary Bureau entre 1936 (quando ele deixou o PHS) e 1947. Ver Ralph Chester Williams, The United States Public Health Service, 1798 to 1950 (Washington, D.C., 1951), p. 446.

25. Marcos Cueto. "Introduction". In: Missionaries of Science: The Rockefeller Foundation and Latin America (Bloomington, 1994), p. xiii. 
países da América Central e da América Latina buscaram a assistência do PHS e da Fundação Rockefeller, cujos financiamentos e pesquisas contribuíram para o estabelecimento de controle federal sobre a saúde em áreas indígenas e regionais mediante o desenvolvimento de infraestrutura em saúde pública.

A United Fruit Company era dona e controlava grande parte da Guatemala, a "república das bananas" por excelência, na primeira metade do século XX. Quando o PHS sondou o país para suas pesquisas nos primeiros anos posteriores à Segunda Guerra, a Guatemala se encontrava em um período de relativa liberdade. Entre 1944 e o golpe de estado de 1954, liderado pela CIA para derrubar o governo eleito, foram estabelecidas leis de proteção ao trabalho e eleições democráticas, e o país passou por uma reforma agrária. O PHS fez parte da iniciativa de utilizar a nação centro-americana para pesquisa científica, tencionando transferir material de laboratório, competências e conhecimento para a elite guatemalteca da saúde pública. ${ }^{26}$

A Guatemala parecia ser o local ideal para o novo estudo por diversas razões. O principal funcionário de saúde pública encarregado de doenças venéreas no país, o dr. Juan Funes, fora capacitado pelo PHS, o que facilitou a parceria, bem como a construção de uma importante infraestrutura em saúde pública no país. À diferença do Alabama, onde o PHS previra encontrar uma grande quantidade de sujeitos com sífilis em estágio latente tardio, a Guatemala oferecia sujeitos que não haviam contraído a doença ainda. Estudos realizados um tanto fortuitamente em 1930 pelo professor George Cheever Shattuck, da Escola de Medicina Tropical da Universidade de Harvard, haviam encontrado poucos casos de sífilis no altiplano guatemalteco e entre o exército do país. Shattuck compartilhava da crença dos funcionários de saúde locais, segundo a qual "a sífilis é mais frequente em latinos (principalmente na Cidade da Guatemala) do que na população indígena e quando se manifesta no segundo grupo, surge em sua forma leve". ${ }^{27}$ Conjecturas raciais acerca da doença, centrais ao projeto no Alabama, também fizeram escola na Guatemala.

26. Ver Jonas, Battle for Guatemala; Stephen Kinzer e Stephen Schlesinger, Bitter Fruit: The Story of the American Coup in Guatemala (Cambridge, Mass., 1999); David McBride, Missions for Science (New Brunswick, 2002).

27. George Cheever Shattuck. "Syphilis and Yaws in Guatemala". In: A Medical Survey of the Republic of Guatemala, ed. George Cheever Shattuck (Washington, D.C. , 1938), p. 142. Shattuck também faz um resumo das crenças médicas sobre a relação entre diferenças raciais e virilidade e ocorrência da sífilis. Ver "Appendix B, The Clinical Case of Syphilis in Various Races,"153-56; Ver também George Cheever Shattuck, "Lesions of Syphilis in American Indians," American Journal of Tropical Medicine 18 (1938): 577 -86. Sobre a relevância ou não do fator racial, ver Reverby, Examining Tuskegee. Ver também Chester North Frazier and 
Graças ao financiamento concedido pelo National Institute of Health ao Pan American Sanitary Bureau, sob a direção do Laboratório de Pesquisas em Doenças Venéreas do PHS (VDRL, na sigla em inglês), este levou a cabo um projeto de pesquisas em cooperação com o Ministério da Saúde da Guatemala, o Hospital Nacional de Saúde Mental e o Ministério da Justiça, que foi benignamente batizado de "Série de Estudos Experimentais sobre a Sífilis em Homens". O enfoque dos experimentos consistia em investigar se substâncias químicas diversas, além das que estavam disponíveis então, poderiam ser usadas como profilaxia para a sífilis após exposição sexual à doença, descobrir a causa dos resultados falso-positivos e demonstrar mais acuradamente quando e como dosagens distintas de penicilina curavam infecções em doenças venéreas diversas. ${ }^{28}$

O PHS e o Pan American Sanitary Bureau designaram Cutler, que fizera parte da pesquisa sobre gonorreia na penitenciária de Terre Haute e trabalhava para o VDRL, para coordenar o estudo na Guatemala com a assistência de Juan Funes, o médico guatemalteco capacitado pelo PHS.

Cutler e Funes tinham dois objetivos. O primeiro era utilizar o que chamavam de "sifilização" com o fim de testar a resposta humana ao "material infeccioso fresco de forma a melhorar a resposta do corpo à doença... (e entender) a superinfecção e a reinfecção". ${ }^{29} \mathrm{O}$ segundo propósito era encontrar maneiras de prevenir a doença imediatamente após a exposição. ${ }^{30}$ Durante a Segunda Guerra, os Estados Unidos haviam provido suas tropas com uma pomada de calomelsulfatiazol nos chamados "pro kits" (kits de profilaxia). O medicamento, porém, era doloroso, o que levou o PHS a se perguntar se poderia substituí-lo por químicos menos tóxicos ou por penicilina. ${ }^{31}$

\section{“Exposição normal” e ciência normal}

Testes em animais, especialmente em coelhos, constituíam um pilar das pesquisas sobre sífilis no século XX, mas não podiam responder a essas prementes

Li Hung-Chiung, Racial Variations in Immunity to Syphilis: A Study of the Disease in the Chinese, White, and Negro Races (Chicago, 1948).

28. "Untitled Report", 24 February 1954, Folder 1, Box 1, Cutler Papers.

29. Ibid., 2, and Sherwood, "Syphilization".

30. Sobre pesquisas para um profilático mais eficaz, ver R. C. Arnold and John C. Cutler, "Experimental Studies to Develop Local Prophylactic Agents Against Syphilis", British Journal of Venereal Diseases 32 (1956), p. 34-36. Para instruções sobre o modo de usar dos "pro-kits" da Segunda Guerra em caso de suspeita de infecção, ver http ://med-dept.com/vd.php (último acesso em 23 de março de 2010).

31. "Untitled Report," 6. 
questões. Os pesquisadores do PHS queriam realizar uma pesquisa onde sabiam que haveria considerável "exposição normal" à doença, como educadamente a chamavam, por parte de seres humanos. Como sujeitos, eles escolheram os quatro grupos usuais dos presos e disponíveis: prisioneiros de uma penitenciária nacional, internos do único hospital de saúde mental da Guatemala, crianças do orfanato nacional e soldados dos quartéis da capital.

A Guatemala havia legalizado a prostituição e "permitia às prostitutas realizarem visitas regulares a homens em instituições penais", conforme informam os relatórios do PHS. ${ }^{32}$ Com a cooperação de oficiais do Ministério da Justiça e do diretor da Penitenciária Central da Cidade da Guatemala, que abrigava quase quinze mil presos, prostitutas com diagnóstico positivo para sífilis ou gonorreia foram autorizadas a oferecer seus serviços aos presos e remuneradas com o dinheiro dos contribuintes norte-americanos através dos fundos do PHS. Em outra série de experimentos, prostitutas não infectadas tiveram inóculos da doença inseridos no colo do útero previamente às visitas sexuais. Os homens eram divididos em grupos e diversas profilaxias biológicas e químicas eram testadas após a presumida infecção. Em caso de diagnóstico positivo, os sujeitos deveriam receber penicilina o suficiente para curar-se.

Como os pesquisadores não tardaram em descobrir, é muito mais fácil manipular coelhos do que seres humanos. A quantidade de homens que parecia ter contraído sífilis após as relações sexuais, mesmo quando acompanhadas da ingestão de álcool, foi considerada insuficiente ${ }^{33}$ (os médicos chegavam a cronometrar o tempo que os sujeitos passavam com as prostitutas e diziam que eles comportavam-se "como coelhos"). Tampouco era fácil controlar as prostitutas - como um pesquisador chegou a lamentar, "infelizmente, nossa doadora fêmea está deixando a profissão para se casar e não se encontra mais disponível". ${ }^{34}$ Outro problema com que se depararam os pesquisadores dizia respeito aos exames de sangue: havia resultados positivos demais, mesmo anteriormente à "exposição normal". Uma vez que precisavam de homens que nunca haviam tido a doença ou que já tinham sido curados, eles descobriram que sua amostra era pequena demais para ter relevância estatística. Sua primeira resposta não foi abandonar a pesquisa, mas, antes, questionar os testes.

Os exames de sangue para diagnosticar a sífilis sempre haviam apresentado problemas, pois o equilíbrio entre sensibilidade e especificidade criava muitos

32. Ibid., 7.

33. John C. Cutler to R. C. Arnold, 5 June 1947, Box 1, Folder 13, Cutler Papers. Toda a correspondência se encontra nesta pasta, a não ser quando indicado.

34. Elliott L. Harlow to John M. Mahoney, 30 June 1947. 
falso-positivos e falso-negativos. Nas palavras dos pesquisadores, "existe uma impressão generalizada de que em certas áreas tropicais e subtropicais há um grande número de casos soropositivos, o que talvez não seja um indicativo preciso da prevalência da sífilis" ${ }^{35}$ Há muito se sabia que a presença da bouba (outra doença provocada por um treponema) e da malária poderiam afetar exames de sangue positivos para sífilis. Na Guatemala, os médicos estavam obtendo resultados positivos para os testes, mas não conseguiam encontrar sinais clínicos ou evidências da doença no fluido espinhal de seus sujeitos. ${ }^{36}$ Como consequência, tinham que realizar repetidos exames de sangue diferenciais (colhendo 10 cc de sangue semanalmente ou quinzenalmente) para determinar se havia ocorrido cura espontânea da doença ou se os exames estavam apenas mostrando o complexo padrão muitas vezes observado em casos de pacientes que haviam contraído sífilis há bastante tempo.

Embora os sujeitos da pesquisa estivessem presos e não houvesse menção a nenhum tipo de consentimento informado, os pesquisadores encontraram resistência. Conforme relataram, "os homens eram, em sua maioria, ignorantes e supersticiosos, e acreditavam que estavam se enfraquecendo" devido às frequentes extrações de sangue. Embora penicilina e pílulas de ferro houvessem sido prometidas, "em suas mentes não havia conexão entre a perda de um grande tubo de sangue e possíveis benefícios de uma pequena pílula". ${ }^{37}$ Essa resistência e a dificuldade de manejar os presos sugeriam que talvez fosse melhor conduzir o estudo das sorologias em outro local.

Com a cooperação do governo guatemalteco, os pesquisadores utilizaram 438 crianças do orfanato nacional, com idades entre seis e 16 anos, com o objetivo de analisar os exames de sangue, não de infectar as crianças com sífilis. ${ }^{38}$ As três crianças que pareciam apresentar sinais de sífilis congênita após repetidos testes e exames foram tratadas com penicilina. Outras 89 crianças tiveram diagnóstico positivo nos testes, mas não apresentaram nenhum sintoma clínico da doença. Depois de determinar que o problema não era derivado dos antígenos utilizados nos exames, os pesquisadores se pronunciaram a favor da utilização de tipos

35. Sacha Levitan et al. "Clinical and Serologic Studies with Reference to Syphilis in Guatemala, Central America", American Journal of Syphilis, Gonorrhea, and Venereal Diseases 36 (July 1952), p. 379.

36. Cutler acreditava que a grande incidência de doenças hepáticas na Guatemala devido à subnutrição também poderia afetar os testes.

37. "Untitled Report," 16.

38. Ibid., 5, and Levitan et al., "Clinical and Serologic Studies", p. 379. 
específicos de exames de sangue com essa população, de forma a descartar fatores de confusão que não eram capazes de identificar. ${ }^{39}$

No entanto, permanecia sem resposta a pergunta acerca da possibilidade do uso da penicilina para profilaxia, não apenas para cura, nos casos de exames de sangue positivos definitivos, em comparação a outras substâncias químicas aplicadas diretamente na genitália. Confrontados com essa e outras questões sobre sorologias e reinfecções pós-tratamento, os médicos decidiram conduzir os experimentos na única instituição de saúde mental do país. Não era possível introduzir prostitutas no local, seguir os internos para observar e cronometrar relações sexuais e nem obter o consentimento das pacientes mulheres para exames físicos, de modo que os pesquisadores planejaram um estudo a partir da inoculação, e não da "exposição sexual". A maior parte dos funcionários da instituição acreditava que a inoculação era apenas outro tipo de droga. ${ }^{40}$

Assim como em Tuskegee, e no hemisfério sul de modo geral, a cooperação foi estabelecida com a instituição, não com os sujeitos internos e suas famílias. E a melhor forma de obter essa cooperação era por meio do fornecimento de suprimentos. Em uma instituição com sérios problemas financeiros e de superpopulação, o PHS forneceu "drogas anticonvulsivantes extremamente necessárias, particularmente Dilatin, já que grande parte dos residentes era epilética". Ele proveu ainda "uma geladeira para material biológico, um projetor de cinema que constituía a única recreação dos internos, copos, pratos e talheres de metal para suplementar o insuficiente material disponível". ${ }^{41}$ Aos sujeitos individuais foram oferecidos cigarros: um pacote inteiro para inoculação, retiradas de sangue ou punção lombar e um único cigarro para "observação clínica". ${ }^{42}$

\section{Criação e introdução do inóculo}

Criar o inóculo da sífilis não era tarefa simples. Um dos métodos consistia em triturar a goma sifilítica dos testículos de coelhos infectados com as cepas bacterianas Nichols e Frew. Isso provou-se extremamente difícil, já que os coe-

39. Levitan et al. "Clinical and Serologic Studies", p. 387. Eles argumentaram que "porcentagens significantemente maiores de reações positivas ou duvidosas eram obtidas através dos testes de Kahn e Mazzini, em comparação ao teste de VDRL”. Hoje a sífilis é diagnosticada com um teste reativo não treponêmico confirmado com um teste treponêmico.

40. "Untitled Report", p. 24.

41. Ibid., p. 25.

42. Ibid., p. 32.

Rev. Latinoam. Psicopat. Fund., São Paulo, v. 15, n. 2, p. 323-349, junho 2012 
lhos tinham que ser trazidos de avião da sede do VDRL, em Staten Island, Nova York, para a Cidade da Guatemala; muitos morriam no caminho ou não desenvolviam uma infecção considerada suficiente. Os pesquisadores tentaram então criar o inóculo a partir de fragmentos de cancros retirados dos internos do hospital psiquiátrico já infectados com sífilis, ou dos soldados que haviam contraído a doença de prostitutas locais não envolvidas no estudo. ${ }^{43}$ Uma vez obtida a amostra (sacrificando os coelhos ou retirando-a do cancro no pênis dos homens), o inóculo vivo tinha que ser feito rapidamente, já que as bactérias espiroquetas duravam apenas entre 45 e 90 minutos fora do corpo. Isso deixava muito pouco tempo para remover o material, centrifugá-lo com um caldo caseiro de bife de coração e prepará-lo para administrá-lo nos sujeitos. Alguns inóculos eram feitos com espiroquetas mortas pelo calor e outros com as bactérias ainda vivas.

A seguir, o inóculo devia ser introduzido no corpo dos sujeitos. Devido ao que foi chamado de "preconceitos locais contra a exibição do corpo para homens, inclusive médicos", nas pacientes mulheres o inóculo era inserido mediante escarificação com agulhas no antebraço, na face ou na boca. Nos homens, a inoculação era com frequência muito mais direta, ao estilo daquilo que os soldados vinham chamando há gerações de inspeção do "braço curto". Eram escolhidos homens com "prepúcio pelo menos moderadamente longo (para manter úmidas as mucosas da membrana)" e que conseguiam manter-se "calmamente sentados ou parados no mesmo local por muitas horas". Durante o experimento, um médico segurava o pênis do sujeito, afastava seu prepúcio e raspava o pênis suavemente com uma agulha hipodérmica, sem chegar a extrair sangue, introduzia uma gaze de algodão (ou um pequeno curativo) e derramava gotas da emulsão sifilítica na compressa e através dela, na pele raspada do pênis, por pelo menos uma hora, às vezes duas.

Esse procedimento foi comparado a outras formas de introduzir a sífilis no corpo, incluindo raspagem do antebraço previamente à administração do inóculo, ingestão de tecido sifilítico misturado em água destilada, remoção de fluido espinhal e reintrodução do mesmo no corpo em uma infusão com o preparado sifilítico e punções venosas da mistura na veia cubital mediana, no antebraço. ${ }^{44} \mathrm{Em}$

43. Para uma discussão sobre os vários tipos de cepas utilizados, ver "Part II Final Syphilis Report", p. 1-5, Box 1, Folder 2, Cutler Papers.

44. "Untitled Report", p. 48. Ver também instruções de R. C. Arnold para John C. Cutler, 21 July 1947. Sobre a história dos vários tipos de técnicas de inoculação, ver Harold J. Magnuson et al., "Inoculation Syphilis in Human Volunteers", Medicine 35 (February 1956), p. 33-82. Sobre as diferenças em relação à inoculação da gonorreia, ver Mahoney et al., "Experimental Gonococcic Urethritis in Human Volunteers". Cutler também era co-autor de ambos esses ar- 
outros estudos de profilaxia realizados em um quartel, os homens foram autorizados a ter relações sexuais com prostitutas não infectadas e então tiveram o inóculo sifilítico introduzido no meato do pênis. ${ }^{45}$ Uma hora depois, foram orientados a urinar e a aplicar diferentes tipos de profilaxia química no pênis. Em outra série de experimentos, o inóculo foi introduzido no colo do útero das prostitutas antes que elas fossem autorizadas a manter relações sexuais com os prisioneiros.

O fervor científico de Cutler era impressionante, uma vez que ele possuía um agudo sentido dos perigos da sífilis. A forma como as inoculações eram feitas variava durante os experimentos, às vezes sendo criadas a partir de um único cancro, às vezes de uma combinação de "doadores", de coelhos ou advindas do corpo de prostitutas, pacientes e soldados infectados. Os pesquisadores ofereceram tipos diferentes de profilaxia para alguns de seus sujeitos; outros foram mantidos sem profilaxia como grupo de controle. Antes de dar início aos experimentos, eles se certificavam que nenhum sujeito tivesse a doença nem houvesse tomado nada contra ela.

Supunha-se que todos os sujeitos infectados tratados com penicilina ficavam curados. O estudo envolveu centenas de homens e mulheres, muitos dos quais tiveram suas fotografias tiradas e anexadas nos arquivos. Alguns sujeitos faziam parte de múltiplos experimentos. O número total de envolvidos (representando sujeitos, não indivíduos) parece ser: "696 expostos à sífilis..., 722 à gonorreia e 142 à cancroide”. Análises preliminares sugerem que 14\% dos participantes do estudo sobre sífilis podem não ter recebido o que era definido como "tratamento adequado", enquanto a porcentagem de cura para gonorreia e cancroide foi de " $99,5 \%$ e $93 \% "$, respectivamente. ${ }^{46}$

\section{Mentiras e omissões}

Como em Tuskegee, mentiras e omissões foram peças centrais deste estudo. Ao escrever para R.C. Arnold, renomado médico do PHS e pesquisador da penicilina, em 1947, Cutler admitiu que eles não estavam contando a muitas pessoas que o inóculo continha a espiroqueta causadora da sífilis. "Como você

tigos. Estudos conduzidos em prisões tendem a usar o termo "voluntários humanos" em seus títulos.

45. Cutler para Mahoney, 27 de dezembro de 1947.

46. Eu não compilei todos esses números. Sou grata ao dr. John Douglas, do CDC, por essa informação em seu relatório. Ver nota 17. 
pode imaginar, afirmou Cutler ao colega, estamos segurando nossa respiração e explicando aos pacientes e a outras pessoas interessadas, salvo algumas exceções, que se trata de um novo tratamento que utiliza soro seguido de penicilina. Esse discurso duplo me mantém em constante estado de alerta". ${ }^{47}$ Em uma segunda carta ele reiterou sua preocupação de que "algumas palavras erradas à pessoa errada aqui, ou até mesmo em casa, podem arruinar o estudo completa ou parcialmente". ${ }^{48}$

Cientistas destacados sabiam que manter segredos, e até mesmo violar a lei, era por vezes necessário para dar prosseguimento a pesquisas. Thomas Rivers, o famoso virologista que dirigiu o Rockefeller Institute for Medical Research Hospital, em Nova Iorque, deixou isso claro em suas memórias, escritas em 1967: "Tudo o que posso dizer é que muitas coisas são contra a lei, mas a lei faz vista grossa quando um homem honrado deseja fazer um experimento científico. Por exemplo, o código criminal da cidade de Nova Iorque declara que injetar uma pessoa com material infeccioso é um delito grave. Pois bem, eu testei uma vacina viva contra a febre amarela na minha própria ala do Hospital Rockefeller. Não era segredo para ninguém e eu posso assegurar a você que as pessoas do Departamento de Saúde de Nova Iorque sabiam que isso estava sendo feito... A menos que a lei ocasionalmente faça vista grossa, não há progresso na medicina". ${ }^{49}$

$\mathrm{Na}$ Guatemala, mais que infringir a lei, o sigilo somou-se às dificuldades que enfrentava um projeto já bastante complicado por si só. Os experimentos sobre profilaxia precisavam determinar a quantidade de inóculo a ser introduzida nos sujeitos, o tempo que levava para a substância entrar no organismo e os tipos de "agentes antissépticos" e "tratamento à base de espiroquetas" a serem utilizados..$^{50}$ Manter um registro atualizado das centenas de sujeitos provou-se difícil, sobretudo no hospital psiquiátrico, onde nomes de pacientes eram esquecidos ou os funcionários os chamavam por alcunhas como "o mudo de São Marcos". Eliese Cutler, ex-aluna do Wellesley College e mulher de Cutler, prestou auxílio ao projeto travando contato com os pacientes e, graças às suas fotografias, "contribuindo para manter as coisas em ordem". Alguns dos internos receberam emulsões de sífilis diversas vezes; outro, conforme deploraram os médicos, "depois da

47. Cutler para Arnold, 5 de junho de 1947.

48. Cutler para Arnold, 27 de junho de 1947.

49. Saul Benison. Tom Rivers: Reflections on a Life in Medicine and Science, An Oral History Memoir prepared by Saul Benison (Cambridge, 1967), p. 187.

50. John C. Cutler. "An Experimental Resurvey of the Basic Factors Concerned in Prophylaxis in Syphilis", unpublished typescript, Box 1, Folder 9, Cutler Papers. 
escarificação e da primeira aplicação da emulsão fugiu do quarto e só foi encontrado duas horas depois, com o curativo ainda no lugar". ${ }^{51}$ Depois de comprovado o êxito na aplicação do inóculo, os pesquisadores deveriam ser "escrupulosos" e se certificar que todos os infectados estavam recebendo penicilina, e os exames de sangue prosseguiam. ${ }^{52}$

Os funcionários guatemaltecos tinham suas próprias exigências. Eles pediram a Cutler para testar e tratar homens nos quartéis do exército, pesquisar a incidência da doença nas terras baixas e fornecer mais penicilina ao país como preço para sua cooperação. Cutler trocou medicamentos contra a malária pelo direito de prosseguir com exames de sangue no orfanato. Todavia, seus chefes no PHS preocupavam-se com o excesso de promessas de suprimentos que ele fazia e suspeitavam que o médico estivesse embarcando em um programa ambicioso demais. Diante da cura aparentemente fácil provida pela penicilina, o PHS vinha travando uma batalha nos Estados Unidos para poder dar sequência ao trabalho com doenças venéreas, de modo que o projeto na Guatemala tornava-se difícil de justificar. ${ }^{53}$ Depois de múltiplas cartas, Cutler se comprometeu a ser cuidadoso e afirmou: "usaremos nosso suprimento moderadamente a fim de poder contar com ele sempre que necessário para os programas de demonstração e para fomentar a boa vontade". ${ }^{54}$

Cutler permaneceu confiante de que tinha em mãos uma mina de ouro para pesquisar. Quando pressionado por seu país a justificar as escarificações e inoculações, ele lembrou a seus supervisores que "sexo normal leva a esse tipo de trauma e lacerações mínimas." Ao escrever para seu diretor-supervisor (o renomado pesquisador do PHS, John F. Mahoney, primeira pessoa a demonstrar o poder da penicilina sobre a sífilis, em 1943), Cutler apontou que "com a oportunidade oferecida aqui para estudar a sífilis do ponto de vista da ciência pura, exatamente como nas pesquisas de Chesney com coelhos, deveria ser possível justificar o projeto caso a resolução do programa profilático não seja possível". ${ }^{55}$

51. "Part III Final Syphilis Report", p. 25, Box 1, Folder 3, Cutler Papers.

52. "Untitled Report", p. 34-39; ver também nota 17.

53. Allan M. Brandt. No Magic Bullet: A Social History of Venereal Disease in the United States Since 1880 (New York, 1987, 1993). Em 1950, o VDRL encerrou todas as pesquisas sobre profilaxia química. Ver John C. Cutler, "Current Concepts of Prophylaxis", Bulletin of the New York Academy of Medicine 52 (October 1976), p. 886-96.

54. Mahoney para Cutler, 18 de novembro de 1946; Cutler para Mahoney, 30 de novembro de 1946; Mahoney para Cutler, 18 de dezembro de 1946.

55. Cutler para Mahoney, 18 de setembro de 1947. 
Nos Estados Unidos, destacados cientistas também estavam esperançosos, de início. Estudos com inoculação realizados no início do século haviam causado muita controvérsia e a partir de 1910 a maior parte deles passou a ser feita em animais, não em seres humanos. ${ }^{56}$ Mahoney disse a Cutler em outubro de 1964: "seu espetáculo está atraindo atenção favorável por aqui. Somos frequentemente indagados sobre o progresso do trabalho. O dr. T. B. Turner, da Universidade Johns Hopkins, quer que investiguemos a patogenicidade da espiroqueta do coelho no homem; o dr. Neurath, da Universidade de Duke, nos pediu para acompanharmos pacientes com seus procedimentos de verificação; o dr. Parran (diretor-geral) e o dr. Moore (principal pesquisador da sífilis da Universidade Johns Hopkins) talvez venham visitá-lo depois do dia primeiro de janeiro". ${ }^{57}$ Harry Eagle, do National Cancer Institute, que havia criado um dos testes de sorologia para sífilis e realizado um importante trabalho sobre a penicilina, também queria fazer parte da pesquisa - sua teoria de que a penicilina poderia ser usada como profilaxia fora testada somente em animais, nunca em seres humanos. Ele ficou tão contrariado por ser impedido de ter acesso aos dados que se queixou ao diretor do PHS. ${ }^{58}$

Entretanto, o estudo na Guatemala provou-se problemático, tanto por razões políticas quanto científicas. Mahoney reconheceu que os dados de Cutler mostravam um desenvolvimento insuficiente da transmissão da infecção e que "as circunstâncias confirmam a conclusão do estudo de Terre Haute, segundo a qual outro fator muito importante, além da presença do organismo, deve operar na transmissão da doença". ${ }^{59}$ No final de 1947, o interesse pela profilaxia decaía nos Estados Unidos e Mahoney advertiu Cutler de que haveria muito pouco dinheiro caso a pesquisa se limitasse a sorologias e à terapia com penicilina. Seria necessário enfocar as supostas diferenças raciais e climáticas com maior amplitude. Mahoney argumentou que "um estudo exaustivo da fiabilidade da sorologia como instrumento diagnóstico entre povos aborígenes das zonas tropicais do continente americano requereria uma abordagem distinta daquela

56. Lederer, Subjected to Science, p. 82-87, sobre os experimentos controversos de Hideyo Noguchi sobre sífilis no Rockefeller Institute em Nova Iorque, em 1911.

57. John F. Mahoney para John C. Cutler, 15 de outubro de 1946.

58. Mahoney para Cutler, 5 de maio de 1947. Eagle trabalhava então no National Cancer e isso pode ter engendrado uma batalha por controle com o PHS. Não há nenhuma evidência de que Eagle tenha participado do trabalho na Guatemala.

59. Mahoney para Cutler, 11 de agosto de 1987. Mahoney conclui: "Está tornando-se evidente que a infecção experimental não pode ser produzida com a freqüência necessária para oferecer um contexto adequado a o estudo sobre profilaxia". 
utilizada presentemente. Para tanto, seríamos obrigados a estudar as nações da América do Sul e Central, os indígenas mexicanos, as tribos indígenas dos Estados Unidos e, finalmente, os negros do sul do país". ${ }^{60}$

\section{Será que eles deveriam fazer isso?}

Além das dificuldades mencionadas, o trabalho que vinha sendo realizado era atravessado por aquilo que especialistas em bioética viriam a chamar de "fator eca". ${ }^{61}$ R. C. Arnold, médico do PHS que supervisionava Cutler de longe, estava mais incomodado que este quanto à ética do projeto. Oito meses após o encerramento do julgamento dos médicos em Nuremberg, ele confidenciou a Cutler: "Estou um pouco, na verdade mais que um pouco, apreensivo sobre o experimento com os doentes mentais. Eles não podem dar seu consentimento, não sabem o que está se passando, e se isso chegar aos ouvidos de alguma organização boazinha vai haver muito alarde. Acho que os prisioneiros ou os soldados seriam melhores opções, pois eles podem dar seu consentimento. Talvez eu seja muito conservador... Além disso, quantas pessoas sabiam do que estava se passando? Tenho consciência de que um paciente ou uma dúzia poderiam ser infectados, desenvolverem a doença e serem curados antes de levantar suspeitas... Não vejo motivos para mencionar no relatório onde ocorreu o trabalho nem o tipo de voluntário utilizado". ${ }^{62}$

Todos os envolvidos no projeto sabiam que estavam se movendo em terreno ético pantanoso. No início dos anos 1940, o National Research Council foi palco de debates sobre ética na pesquisa sobre gonorreia realizada na prisão Terre Haute. O historiador Harry Marks argumenta que o PHS sabia que essas pesquisas tinham que contar com uma sólida base metodológica e ser cientificamente frutíferas para justificar o risco que corriam os presos. ${ }^{63}$ Por outro lado, o PHS sabia que havia pouquíssimas maneiras de obter essa informação e de encontrar um meio de frear

60. Mahoney para Cutler, 8 de setembro de 1947.

61. Jussi Niemela. "What Puts the 'Yuck' in the 'Yuck Factor", Bioethics, online 25 February 2010, www3. interscience.wiley.com (último acesso em 25 de março de 2010).

62. R. C. Arnold para Cutler, 19 de abril de 1948, Box 1, Folder 17, Cutler Papers.

63. O National Research Council, criado em 1916, supervisiona políticas em pesquisas científicas para o governo dos Estados Unidos. Durante a Segunda Guerra o conselho possuía um subcomitê do Committee on Medical Research, cujo enfoque eram pesquisas sobre doenças venéreas. Ver Marks, Progress of Experiment, p. 100-105. 


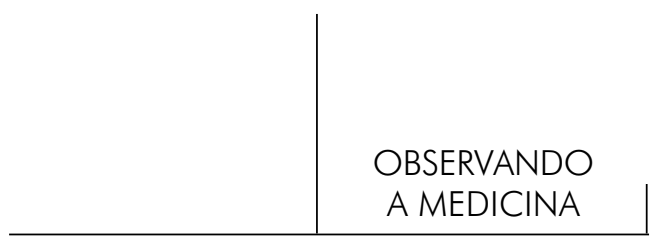

a propagação da sífilis por profilaxia antes de a doença se estabelecer, em vez de simplesmente curá-la posteriormente. Embora as pesquisas sobre gonorréia na Terre Haute tivessem falhado, eles ainda tinham esperanças de que o êxito em novos testes para gonorréia e sífilis na Guatemala provaria que valia a pena ter corrido riscos.

O especialista em malária G. Robert Coatney, que realizara pesquisas sobre a enfermidade em prisões, visitou o projeto em fevereiro de 1947. Em um relatório que enviou a Cutler após seu regresso aos Estados Unidos, ele explicou que colocara o diretor Thomas Parran a par do estudo na Guatemala e que este afirmara, "com um brilho maroto no olhar... 'sabe, não poderíamos fazer um experimento como esse aqui neste país" ${ }^{\text {" }}{ }^{64}$

Cutler também reconhecia que outros especialistas em sífilis acreditavam que "não era possível conduzir eticamente" experimentos em humanos sobre o uso da penicilina para prevenir a sífilis que requeriam inoculação com a doença. Preocupado com o fato de a discussão sobre o problema ético estar ocorrendo nos Estados Unidos no momento em que informações sobre a subvenção ao programa na Guatemala eram publicadas no Journal of the American Medical Association, Cutler disse a Mahoney: "está se tornando tão claro para nós quanto parece sê-lo para você que não seria aconselhável termos muitas pessoas envolvidas neste trabalho, de forma a impedir que circulem rumores e que se escreva prematuramente sobre o tema. Estamos um tanto quanto inquietos com a possibilidade de que algo que possa afetar adversamente a continuação do programa seja dito". ${ }^{65}$

Mahoney permanecia preocupado e advertiu Cutler de que circulavam nas altas esferas boatos sobre o que se passava na Guatemala. "Espero que você não hesite em encerrar o trabalho experimental caso haja interesse desmedido nesta fase do estudo", completou. Mahoney, assim como Arnold, parecia não se preocupar com as pesquisas com prostitutas na penitenciária, mas se mostrava mais apreensivo com a política e a moralidade dos estudos de inoculação realizados na instituição mental. ${ }^{66}$

$\mathrm{O}$ fato de a pesquisa requerer tanto esforço para induzir a infecção era outro problema, já que ela não podia ser replicada em nenhum outro local. Um ano e meio após o início do projeto, Mahoney disse a Cutler que "em se tratando de

64. G. Robert Coatney para Cutler, 17 de fevereiro de 1947, Box 1, Folder 17, Cutler Papers.

65. Cutler para Mahoney, 17 de maio de 1947, Box 1, Folder 11, Cutler Papers.

66. Mahoney para Cutler, 30 de junho de 1947. O julgamento dos médicos em Nuremberg estava acontecendo entre 9 de dezembro de 1946 e 20 de agosto de 1947, mas nem Mahoney nem Cutler fazem menção a ele em sua correspondência. 
sífilis, a menos que se possa transmitir a doença facilmente sem fazer uso de escarificação ou implantação direta, as possibilidades de estudar os sujeitos não são muito boas". Os procedimentos, apontou, são "drásticos, ultrapassam os limites da transmissão natural e não podem servir de base para o estudo de um agente profilático localmente aplicado". ${ }^{67}$ Cutler fez o melhor que pôde para testar o estudo de múltiplas maneiras, para usar diferentes cepas bacterianas, alternando entre doadores humanos e animais, e para enfatizar a replicação. ${ }^{68}$

Enquanto Cutler seguia com uma série de estudos diferentes, seus supervisores no PHS estavam bastante conscientes de que o projeto tinha que ser encerrado. Os suprimentos escasseavam e o uso crescente da penicilina diminuiu o apoio político a esse tipo de pesquisa. Em 1948, Cutler foi avisado de que deveria finalizar o trabalho, deixar o material de laboratório para as iniciativas de controle de doenças venéreas na Guatemala e voltar para casa a fim de ser reposicionado em outra localidade. Com o tempo, Cutler e seus colegas viriam a escrever artigos sobre suas descobertas em sorologia e um colega publicaria alguns detalhes do estudo em um jornal de saúde pública em língua espanhola. ${ }^{69}$ Cutler arquivou seu relatório final e as centenas de fotografias tiradas por sua esposa, único registro que restou de todos os anos que dedicou à carreira de pesquisador. ${ }^{70}$ Os esforços extraordinários que ele havia feito para produzir a sífilis e compreender os vários tipos de profilaxia foram enterrados em seus arquivos.

\section{Que diferença faz?}

O dr. Joseph Earle Moore estava certo ao afirmar que a cura para a sífilis deixara muitas questões sobre a doença em aberto. Embora os trabalhos de Cutler tenham contribuído para refinar os testes sorológicos e sugerido uma profilaxia química mais eficiente, eles tiveram pouco impacto nas pesquisas sobre sífilis.

67. Mahoney para Cutler, 8 de setembro de 1947, Box 1, Folder 13, Cutler Papers.

68. Arnold para Cutler, 30 de julho de 1947, Box 1, Folder 11, Cutler Papers.

69. Sacha Levitan et al. "Clinical and Serologic Studies with Reference to Syphilis in Guatemala Central America I", American Journal of Syphilis, Gonorrhea, and Venereal Diseases 36 (July 1952), p. 379-87; John C. Cutler et al. "Studies on the Comparative Behavior of Various Serologic Tests for Syphilis II", ibid. 36 (November 1952), p. 533-44; Joseph Portnoy et al. "Clinical and Serologic Studies with Reference to Syphilis in Guatemala, Central American III", ibid. 36 (November 1952), p. 566-70.

70. Juan Funes et al. "Serologic and Clinical Studies in Syphilis in Guatemala, Central America, II", Boletín de la Oficina Sanitaria Panamericana 34 (January 1953), p. 14-18. 


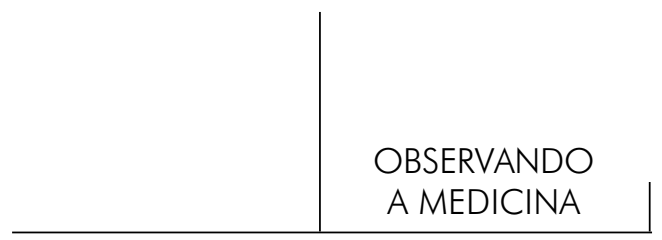

Cinco anos após o fim do estudo da Guatemala, em 1953, Cutler faria junto com Harold Magnuson, do PHS, outro estudo com inoculação na prisão de Sing Sing, em Nova Iorque, com sessenta e dois "voluntários". Como na Guatemala, ele usou organismos virulentos e organismos mortos ao contato com o calor, feitos a partir de testículos de coelho moídos. Mas essas inoculações foram feitas de forma intracutânea e subcutânea. Não havia ninguém raspando o pênis desses homens norte-americanos, nem mesmo na prisão. E todos aqueles diagnosticados com a doença foram tratados com penicilina. A pesquisa em Sing Sing foi conduzida para responder a algumas perguntas sobre reinfecção e para verificar se, após receber tratamento para sífilis e em seguida receber um "reforço" da doença, desenvolvia-se imunidade contra futura infecção. O extensamente citado e divulgado relatório sobre o trabalho em Sing Sing cobriu grande parte da história da inoculação com sífilis, mas não fez menção alguma às pesquisas na Guatemala. ${ }^{71}$

Por que então o trabalho realizado na Guatemala faz alguma diferença, à parte a história secreta dos vínculos de Cutler com Terre Haute, Guatemala, Sing Sing e Tuskegee, e nosso sentimento de horror diante do que foi feito sem o consentimento das pessoas envolvidas? Será que precisamos de mais uma história terrível sobre os "maus velhos tempos" da pesquisa médica antes da criação dos conselhos de ética institucionais que, supõe-se, protegem os sujeitos humanos? Será que esses fatos sugerem que os responsáveis pela formulação de políticas sobre o uso de sujeitos humanos devem reconsiderar o que ocorreu em Tuskegee?

O estudo na Guatemala faz diferença por diversas razões. Ele demonstra as relações entre os Estados Unidos e o resto do mundo no âmbito da saúde pública. Houve intercâmbio de ideias, de práticas, de justificativas e de pesquisadores atravessando fronteiras. ${ }^{72}$ Determinadas formas de tratar sujeitos de pesquisa em um local e mentiras e omissões permitidas em outro circularam e fizeram parte da criação de uma cultura de pesquisa. Não foram apenas práticas de saúde pública, mas também pesquisas em saúde pública que cruzaram as fronteiras de um país a outro. O que levanta mais uma vez a questão sobre se os padrões observados nos Estados Unidos são mantidos quando seus pesquisadores vão para o exterior. ${ }^{73}$

71. Magnuson et al. "Inoculation Syphilis". Outro médico que fez parte do projeto foi Sidney Olansky, que dirigiu o trabalho em Tuskegee nos anos 1950. Para mais sobre Olansky e Cutler, ver Reverby, Examining Tuskegee.

72. See Warwick Anderson. "Pacific Crossings: Imperial Logics in United States' Public Health Programs". In: Colonial Crucible, ed. McCoy and Scarano, p. 277-87.

73. Há um imenso debate político e bioético sobre essa questão. Ver, por exemplo, Jennifer S. Hawkins and Ezekiel J. Emanuel, eds., Exploitation and Developing Countries: The Ethics of Clinical Research (Princeton, 2008); Ruth Macklin, Double Standards in Medical Research in Developing Countries (Cambridge, 2004); e Reverby, Examining Tuskegee, p. 228-30. 
Somente estando a par deste contexto podemos entender as decisões tomadas pelo PHS. Mesmo estando desconfortável sobre o que estava sendo feito na Guatemala, o órgão permitiu que o trabalho continuasse por dois anos. Diante disso, é bem possível que o PHS tenha considerado o projeto no Alabama - onde ninguém foi infectado pelos médicos - como relativamente benigno.

A história do trabalho na Guatemala também confirma a não infecção no estudo Tuskegee, já que põe em relevo as dificuldades de infectar indivíduos com sífilis em um projeto científico. Os extremos a que Cutler e seus colegas tiveram que chegar para transmitir a doença aos pacientes mentais, aos presos e aos soldados na Guatemala e, mais tarde, de modos menos atrozes, em Sing Sing, nos permite dizer que isso não ocorreu em Tuskegee. Certamente os sobreviventes do estudo no Alabama se recordariam se tivessem sido submetidos a injeções e raspagens no pênis. Em todos os registros (tanto nos arquivos federais quanto nos arquivos da Universidade de Tuskegee) que listam aspirinas, suplementos de ferro e frascos de pílulas enviados a Tuskegee, não há menção alguma a dinheiro gasto em coelhos, na criação de inóculos em laboratório ou outras iniciativas nesse sentido.

Ao mesmo tempo, o caso da Guatemala torna mais fácil imaginar que médicos do governo possam ter infectados homens no Alabama. Os pesquisadores do PHS no período eram tecnicamente capazes de infectar homens com sífilis, ainda que o procedimento fosse mais trabalhoso do que gostariam. E eles eram moralmente capazes de fazê-lo, já que sua fé na causa levou-os a infectar pessoas com essa doença terrível sem seu consentimento e sem seu conhecimento, ao menos aquelas que não tinham poder e nem a pele branca. Estes fatos complicam tanto a história de Tuskegee que eu os omiti propositalmente de meu livro Examining Tuskegee, para que não fosse difícil demais explicar que os homens do Alabama não foram infectados.

Muitas vezes, os responsáveis pela formulação de políticas escolhem a dedo relatos históricos distintos para justificar suas decisões. Os historiadores podem se dar ao luxo de deleitar-se com contextos e fatos conhecidos, enquanto outros criam leis, regulações e significados a partir de nosso trabalho. O caso Tuskegee é, com frequência, mal recordado e contado de forma simplista. Os estudos com inoculação na Guatemala contextualizam o trabalho em Tuskegee, mas podem também fomentar o medo de pesquisas médicas. Se as barulhentas justificativas para o controle sobre as pesquisas médicas têm sido "não podemos esquecer Tuskegee", pode-se apenas imaginar o que seriam se os estudos na Guatemala fossem parte do cenário. Por mais que possamos ficar enojados e revoltados com essas pesquisas, elas nos obrigam a considerar a forma como contamos essas histórias, assim como as políticas que formulamos atualmente, uma vez que 


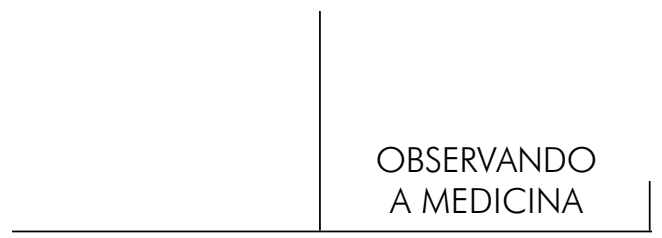

muitas pesquisas atuais são globais e os riscos e benefícios da experimentação precisam ser constantemente recalibrados. ${ }^{74}$

Adendo de Outubro de 2010

A publicação deste artigo provocou ultraje no mundo todo quando os fatos sobre o estudo chegaram às altas esferas do governo norte-americano, e um pedido formal de desculpas foi feito junto ao governo da Guatemala e seu povo no dia $1^{\circ}$ de outubro de 2010. Ao final de junho de 2010, antes da publicação do artigo, entreguei uma cópia ao dr. David Sencer, antigo diretor do Centers for Disease Control and Prevention, o qual eu havia entrevistado sobre o estudo Tuskegee a fim de checar informações médicas. ${ }^{75}$ Depois da leitura, o dr. Sencer pediu minha permissão para que outros membros do CDC tivessem acesso ao artigo antes da publicação. Concordei e o artigo foi lido por outras pessoas do órgão, que conversaram comigo sobre ele e se mostraram bastante apreensivas. Não houve nenhum esforço para impedir a publicação. O especialista em sífilis dr. John Douglas foi enviado para analisar os registros e prover um relatório que verificasse minhas descobertas. ${ }^{76} \mathrm{Meu}$ artigo não publicado e o relatório de Douglas chegaram, por meio do CDC, ao National Institutes of Health, ao Department of Health and Human Services (DHHS), ao Department of State e à Casa Branca. Em primeiro de outubro de 2010, a secretária de Estado, Hillary Rodham Clinton, e a secretária do DHHS, Kathleen Sebelius, apresentaram um pedido formal de desculpas pelo estudo à Guatemala, que classificaram de "abominável", "não ético" e "condenável”. ${ }^{77} \mathrm{O}$ presidente Barack Obama ligou para o presidente guatemal-

74. A questão da proteção ao sujeito humano é ainda mais relevante agora que a porcentagem de testes no exterior para drogas nos Estados Unidos tornou-se mais comum. Ver "Concern over Foreign Trials for Drugs Sold in U.S." New York Times, 21 June 2010, A14; Adriana Petryna, When Experiments Travel: Clinical Trials and the Global Search for Human Subjects (Princeton, 2009).

75.Para maiores detalhes, ver Susan M. Reverby, "After the Media Frenzy: Preventing Another 'Guatemala"', Bioethics Forum: A Service of the Hastings Center, 6 October 2010, http:// www.thehastingscente.org/Bioethicsforum/Post.aspx ? id= 4919\&blogid= 140 (último acesso em 6 de outubro de 2010 ).

76. John M. Douglas. "Full Centers for Disease Control and Prevention Report on the 1946-1948 U.S. Public Health Service Sexually Transmitted Disease (STD) Inoculation Study," http:// www.hhs.gov/1946inoculationstudy (último acesso em 15 de outubro de 2010).

77. "Joint Statement by Secretaries Clinton and Sebelius on a 1946-1948 Study", http:// www.hhs.gov/1946inoculationstudy (último acesso em 15 de outubro de 2010). 
teco Alvaro Colom "para expressar seu profundo pesar". ${ }^{78}$ Os diretores do National Institutes of Health e do CDC classificaram o estudo de "lamentável e profundamente devastador". ${ }^{79} \mathrm{O}$ Institute of Medicine e a President's Bioethics Commission foram solicitados a fornecer um relatório sobre o ocorrido e sobre os mecanismos de proteção de sujeitos atualmente em voga. $\mathrm{O}$ frenesi midiático sobre o assunto deu a volta ao mundo com cobertura e editoriais nos principais jornais e mais de 15.000 matérias publicadas. O futuro nos dirá quais serão os efeitos deste artigo na proteção de sujeitos humanos no mundo todo.

\section{Resumos}

(Syphilis from "normal exposure" and inoculation: a physician on the Tuskegee Study Team in Guatemala, 1946-1948)

Between 1946 and 1948, the United States Public Health Service and the PanAmerican Sanitary Office, in cooperation with public health officials of the Guatemalan government, conducted a study on the use of penicillin as a possible prophylaxis for syphilis, gonorrhea and cancer. The "subjects" of the study (prisoners, mental patients and Guatemalan soldiers) were inoculated with these diseases and also acquired them through contact with infected prostitutes. The fraud was part of the study and ethical abuses were discussed at the US Public Health service. The study results were not published.

Key words: Syphilis, Guatemala, public health, study, penicillin

(La syphilis par 'exposition normale' et par inoculation: un médecin de l'équipe d'étude Tuskegee au Guatemala, 1946-1948)

Entre 1946 et 1948, le Public Health Service des États-Unis (PHS) et l'Oficina Sanitaria Panamericana, en collaboration avec les responsables de la santé publique du gouvernement guatémaltèque, ont mené une étude sur l'utilisation de la pénicilline à titre préventif contre la syphilis, la gonorrhée et le cancer. Les sujets de l'étude - des prisonniers, des malades mentaux et des soldats guatémaltèques - ont été inoculés directement avec ces maladies, ainsi que par contact avec des prostituées infectées.

78. "Read-out of the President's Call with Guatemalan President Colom,” http://www.hhs.gov/ 1946 inoculationstudy (último acesso em 15 de outubro de 2010).

79. Thomas R. Frieden and Francis S. Collins. "Intentional Infection of Vulnerable Populations in 1946-1948", Journal of the American Medical Association, publicado online em 11 de outubro de 2010. doi:10.1001/jama.2010.1554 e http://www.hhs.gov /1946inoculationstudy. 


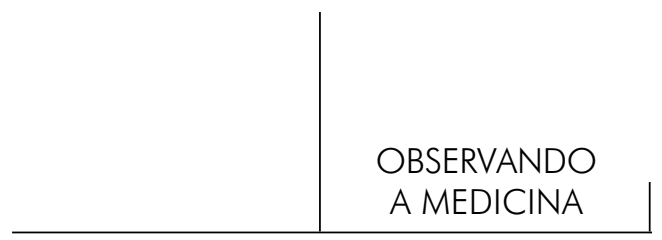

Cette fraude était partie intégrale de l'étude, dont les abus éthiques ont été discutés par le PHS. Les résultats de l'étude n'ont jamais été publiés.

Mots clés: Syphilis, Guatemala, Santé publique, pénicilline

(Sífilis por 'exposición normal' e inoculación: un médico del equipo de la investigación Tuskegee en Guatemala, 1946-1948)

Entre 1948 y 1948, El Servicio de Salud Pública de los Estados Unidos (PHS) y la Oficina Sanitaria Panamericana, con la colaboración de funcionarios de la salud pública del gobierno de Guatemala realizaron un estudio sobre el uso de la penicilina como una profilaxis posible para el sífilis, gonorrea y cancro. Los "sujetos" del estudio - prisioneros, enfermos mentales y soldados guatemaltecos, fueron inoculados con esas enfermedades y también a través del contacto con prostitutas infectadas. El fraude fue parte del estudio y los abusos éticos fueron discutidos en el PHS. Los resultados del estudio no fueron publicados.

Palabras clave: Súfilis, Guatemala, salud pública, penicilina

(Syphilis Übertragung durch, natürlichen Kontakt' und durch Impfung: Ein Arzt der Forschungsgruppe Tuskegee, in Guatemala, 1946-1948)

Zwischen 1946 und 1948 haben das öffentliche Gesundheitswesen der USA (PHS) und die Oficina Sanitaria Panamericana, mit Hilfe von Angestellten des öffentlichen Gesundheitswesens der guatemaltekischen Regierung, eine Studie über die Anwendung von Penizillin als mögliches Vorbeugungsmittel gegen Syphilis, Gonorrhöe und Krebs durchgeführt. Die Versuchspersonen - Gefangene, Geisteskranke und guatemaltekische Soldaten - wurden mit dieser Krankheit „geimpft“ und durch kranke Prostituierte angesteckt. Der Betrug (El engaño) war Teil der Studie und die ethischen Missbräuche wurden im PHS diskutiert. Die Ergebnisse der Studie wurden nicht veröffentlicht.

Schlüsselwörter: Syphilis, Guatemala, öffentliche Gesundheitswesen, Penizillin

\section{SusAn M. Reverby}

Doutora em estudos americanos pela Boston University; professora de estudos de mulheres e de gênero, no Wellesley Collge, e realiza a pesquisa "Escapando do drama da investigação médica e do melodrama dos direitos humanos".

e-mail: sreverby@wllesleu.edu 